ligada às I grejas, aos formadores de opinião pública da elite eà ação dos meios de comunicação. Tudo isso, além da miséria da maioria que os obriga a zelar pela própria sobrevivência mais do que exercitar autonomia de seus corpos e desejos. Haveria que investigar isso melhor; levanto outra hipótese, apesar da força e da freqüência com tem sido esgrimida a potência controladora do biopoder.

Julgo haver uma relação estreita entre a gênese de sistemas de informação em saúde no Brasil e dois outros fatores. $O$ mais rel evante, me pare ce, foi a lógica de remunerar o ato médico e as práticas em saúde com base em procedimentos: consulta médica, cirurgia, exames, internação, etc. Muito da lógica dos bancos de dados do SUS ainda guarda influência dessa racionalidade. 0 mercado remunera por ato, por procedimento, assim todo ato ou procedimento deverá ser registrado e arquivado para eventual auditoria: Inamps... Essa cultura foi um pouco modificada pela introdução de al gumas recomen dações mais amplas de alguns programas de saúde pública: saúde da família, hipertensão arterial, etc.

0 outro fator influente na gênese do núcleo deinformação ede informática foi a própria SaúdePública tradicional, entrenós rebatizada eressuscitada com o inequívoco nome de“"Vigilância em Saúde: vigilância sanitária e epidemiológica". Pois bem, parte da tradição de nosso modo de acumular ede registrar informações decorredessa tradição: doenças de notificação compulsória, dados cartoriais sobre produção e consumo de produtos e sobre organização do espaço urbano. Saúde Pública e sua ligação umbilical à busca de legitimação social e política do Estado brasileiro. Além disso, a Saúde Pública no Brasil tem seconstituído muito em função deapoiar a construção de uma base sustentável para o crescimento econômico e organização capitalista da produção.

A gênese da área de informação e informática, suspeito, foi constituindo-se segundo houve necessidade de sistematizar esse tipo de dados procedimentos a serem pagos e informação para a vigilância.

Por último, o terceiro comentário: um assunto que não é central na estrutura do ensaio em discussão, mas que julgo conveniente insistir sobre o tema. $N$ ão acredito na possibilidade de constituir-se uma "ciência da saúde" por contraposição a uma "ciência da doença". O objeto de conhecimento edeintervenção de todo o campo da saúde - inclusive o da Saúde Coletiva ou da Promoção à Saúde - inevitavelmente, guarda refe rência ao risco, à vulnerabilidade, à doença e à morte. Do que necessitamos não é de fugir desse elemento concreto, mas de redefinir o sentido e significado desses conceitos, particularmente quando reconhecemos que estão encarnados em sujeitos - indivíduos e coletividades. Penso que saúde é o objetivo do conhecimento e do trabaIho em saúde, sua finalidade. N osso campo, portanto, está condenado a lidar com processo de co-produção de saúde/doença/risco evulnerabilidade. Não há como fugir dessa fragilidade da vida, não éconvenienteinventar-selinhas defuga para este outro paradoxo.

Bem, me desculpem qualquer coisa... Foi um prazer, uma oportunidade para aprender de maneira estimulanteelúdica, ler epensar ecomentar o trabalho de vocês. Parabéns e obrigado.

\section{Caleidoscópio info-interdisciplinar: discurso no entremeio}

Info-interdisciplinary kaleidoscope: midfield discourse

\section{Evelyn Goyannes Dill Orrico ${ }^{4}$}

0 artigo para debate objetiva compreender a gênese dos limites atuais das práticas de Informação e Informática em Saúde, partindo do pressuposto de que essa práxis informacional não dá conta da complexidade dos processos que envolvem o trinômio saúde-doença-cuidado.

As autoras atribuem à limitação dessas práticas a dificuldade que o Estado brasileiro tem em ampliar sua capacidade de resposta para a resolução dos problemas em saúde porque 0 processo que envolve Informação e Informática em Saúde integra questionamentos mais amplos sobre os modos de produção de conhecimento na contemporaneidade do que os que foram até o momento considerados. A novidade que apresentam repousa na proposta de atribuir papel relevante à crise de paradigmas, propondo estabelecer o que denominam intercampo de informação e informática em saúde.
${ }^{4}$ Departamento de Processos Técnico-D ocumentais, Programa de Pós-Graduação em M emória Social, UNIRIO.evelynorrico@unirio.br 
Essa proposta pressupõe a implantação de uma política de informação e informática em saúde que se pauteem uma organização em rede, composta por três tipos de elementos: espaços de ensino e pesquisa; espaços governamentais e de administração em saúde; e espaços de conquista e exercício da cidadania. Além disso, essa política, controlada socialmente, teria como finalidade contribuir para estabelecer um processo democrático emancipador do homem brasileiro que provocaria uma gestão qualificada do Sistema Ú nico de Saúde, de fato comprometido com a melhoria da saúde da população.

A proposta é oportuna e propõe interlocução entre três campos distintos, o queme sugere, a título de abrir o debate, introduzir a análise sobre dois conceitos que possam fomentar a discussão: rede e discurso.

\section{Rede e discurso}

Etimologicamente ${ }^{1}$ fal ando, redesignifica um tipo deentrelaçamento defios com o qual as muIheres na Renascença prendiam os cabelos, ou usavam sob a camisa, à guisa de soutiens. Esse significado expandiu-se, o queem Semântica significa que o termo ampliou seu quadro de significado para designar os fios têxteis de uma maIha. Ampliou-se ainda mais para designar a maneira como se fixam troncos no solo e se trançam os fios entre eles de modo a estabelecer uma resistência para barragens.

Continuando essa expansão de significado, no século XIX, o conceito de rede passou a representar 0 entroncamento de canais com água, com o intuito de abastecer a cidade de Paris, e daí generalizou-se para uma concepção cada vez mais abstrata, atéchegar a se constituir como um pensamento da tecnologia francesa.

Esse conceito ajudou a compreender ea visualizar várias áreas do conhecimento, expandindo o si gnificado para um campo ainda mais abstrato do que o anterior e passou a designar uma forma de gerenciamento de governos.

0 conceito de rede implica um espaço representacional no qual há uma pluralidade de pontos que se ligam por uma pluralidade de ramificações sem que, por definição, nenhum ponto seja privilegiado em relação a outro. Cada um de seus entroncamentos abre possibilidades de criar outras ligações e assim sucessivamente.

Essa configuração de troncos - ou nós nos quais passam fios - ou elos - que os ligam a outros troncos, assim sucessivamente representando a imagem de uma rede de comunica- ção, viabiliza representação ideal para uma realidadeque se pretendenão hierárquica. 0 problema, a nosso ver, reside exatamente aí.

0 que percebemos em nossas análises junto a grupos de pesquisa estruturados em rede éque essa é uma configuração idealizada, mas na prática alguns nós atuam como pólos de concentração de força, implicando uma organização hierárquica mesmo que não explicitamente determinada. No caso em tela, como os três nós envolveriam a) espaços de ensino e pesquisa; $b$ ) espaços governamentais e de administração em saúde; e c) espaços de conquista e exercício da cidadania, que, por si só, já estão submetidos a correlações de forças diferentes, pode-se supor quea organização hierárquica ocorreria demodo ainda mais evidente.

Um segundo conceito a ser aqui discutido éo dediscurso que, por via de conseqüência, encontra-se no cerne, não só dessa, mas de todas as organizações.

Segundo Possenti² a análise da palavra discurso no campo das ciências humanas demandaria levar em conta aspectos históricos, antropológicos sociológicos, além dos cognitivos, todos eles entrelaçados com a língua. Esse autor aponta ainda que a produção discursiva ocorreria em situações, por ele denominadas de "concretas", conferindo uma garantia de realidade a essa produção. Fazemos a correlação entrea proposta de intercampo de informação e informática em saúde com o que diz Possenti porque estamos refletindo sobre uma situação de informação para resolução de problemas concretos de amplo segmento da sociedade.

A prevista interlocução entre três campos distintos nos remete à proposta de Foucault ${ }^{3} \mathrm{a}$ respeito dos mecanismos de interdição do discurso que, em última instância, regulam a sua própria produção, por limitarem o que deve ser dito e por quem durante os processos de produção discursiva.

Considerando a organização em rede, e considerando ainda nossa contemporânea configuração de produção de saberes, quais seriam, então efetivamente, os nós da rede com suficiente legitimação para implantar os fundamentos de construção de políticas públicas?

Como, então, sair desse ciclo aparentemente vicioso?

\section{As contribuições de Bakhtin}

As autoras do artigo central real izaram um estudo exploratório dos processos sociopolíti- 
cos e epistemológicos que estão presentes na construção histórica das redes de informação em saúde, que por sua vez se constituem pela informação científica e tecnológica em saúde, pela informação e informática em sistemas e serviços de saúde e pelas informações sociopolíticas e econômicas, e por isso ampliam, ao mesmo tempo em que conformam, um espectro amplo de discussão.

Chamou-meparticularmentea atenção o trecho em que as autoras comentam sobre a informação vir sendo tratada de modo desvinculado do contexto histórico, político-social-econômico. Desse modo, a 'informação em saúde' restringir-se-ia ao âmbito da tecnicidade, apresentada como 'despolitizada' e'neutra'. O utra informação que também despertou a atenção foi a seguinte: quando as variáveis socioeconômicas estão previstas na coleta de dados, elas são as que apresentam maiores problemas de qualidade, certamente por não serem adequadamente trabalhadas, ou levadas em conta.

Essas afirmações me fizeram recorrer a Mikhail Bakhtin, autor russo, do início do século $X X$, mas que hojetem tido sua formulação fortemente considerada em virtude da atualidade de suas observações e discussões teóricas. Ele pode nos ajudar a clarear a discussão, em virtude de propor um modelo de compreensão da linguagem que pressupõe sua inserção em contexto sócio-historicamente situado.

Se estamos tratando de um trinômio que envolve a ação de informar, é preciso considerar o discurso sócio-historicamente contextualizado. A proposta de Bakhtin 4 éanterior à de Foucault, mas as duas dialogam entre si. No entanto, o que me faz considerar Bakhtin o interlocutor preferencial, ao invés de Foucault, éperceber que, por viver em período histórico-político particularmente revolucionário, a Rússia do início do século XX, ele propôs que, para dizer algo novo, a forma de dizer também haveria de ser nova.

É essa orientação que 0 aproxima da proposta posta em debate: estamos em uma nova configuração de produção do conhecimento, é preciso que a forma discursiva dessa produção sejaigualmente diferente enova.

\section{Informação-formação}

Não é de hoje que conhecemos as distorções históricas dos aspectos de saúde brasileiros e as tentativas em trazer à cena aquele que é o mais diretamente atingido, a soci edade. N essas tentativas, colocam-se em jogo várias "realidades", advindas das diversas comunidades discursivas que entram no jogo comunicacional. No texto em debate, a força é colocada na informação voltada para os organismos gestorese, nesse caso, a informação pode ser admitida, então, como informação voltada para a gestão.

0 que se pode apresentar como contribuição para o debateé a utilização de informação como formação, aqui entendida como meio de compreensão não só da realidade, mas das perspectivas desolução. Deixemos claro que estamos pensando em formação voltada para os atingidos pela gestão da saúde, ou seja, a sociedade, visto que ela está no bojo das discussões sobre saúde, a partir da proposta introduzida pelo SUS.

A partir do ingresso eda possibilidade real de interferência denovos agentes nas decisões sobre as políticas públicas de saúde, os discursos produzidos pelos distintos agentes sofrem distintas formas de interdição.

\section{Discussão}

As autoras apontam com muita propriedade que um ponto de partida é a reconstrução do momento em que acontece a diferenciação entre a saúde entendida como dimensão fundamental da vida humana e saúde entendida como setor especializado einstitucionalizado do conhecimento. I sso reforça a proposta que pretendemos aqui agregar, qual seja a da correlação entre a construção de modelos significativos que estejam sócio-historicamente contextualizados.

Desse modo, à afirmação de que o regime de informação que estabelece os modos preferenciais de definição, preservação, transmissão e uso das informações em saúde teria, como resultante, uma dupla orientação epistemológica epolítica, gostaríamos de observar um outro aspecto.

Acreditamos, ao contrário, que esse regime é fruto, el e mesmo, denovas configurações epistemológicas ainda hegemônicas no campo da saúde e que impedem a adequada re inserção nos novos paradigmas epistemológicos.

\section{Considerações intermediárias}

Consideramos nossas conclusões como intermediárias porque este é um debate ainda em curso. A título de encerramento do texto, mas não da discussão, podemos dizer que a construção discursiva é ponto fundamental em qualquer âmbito quando se fala em informação. Ao se pautar no trinômio saúde/doença/cuidado, com ênfase nas informações sobre sinais, sintomas, 
signos e práticas curativas, o sistema de informação mostra-se como fruto do modelo antigo, mas ainda hegemônico. Em tempos de novas e mais efetivas práticas de produção de saberes, e sobretudo em meio à atual configuração epistêmica, a construção do significado compartilhado entre os agentes envolvidos no processo informacional é condição sine qua non para o sucesso. Assim, um sistema que descartea inserção dos imbróglios discursivos socialmente contextualizados tenderá a não atender as expectativas. N esse sentido, reforço a compreensão de que conhecer o universo discursivo dos agentes envolvidos é o passo fundamental nesse processo informacional.

Esse universo discursivo deve ser reforçado pelas informações em saúde dirigidas de modo adequado para a sociedade civil. Só re-construindo o discurso estabelecido nas zonas de poder é que a sociedade civil organizada poderá - de fato - exercer o seu papel.

Concordamos, portanto, que devehaver uma reformulação da matriz cognitiva da informação em saúde a partir do reconhecimento dos modos de construção, diferenciação e interação entre as informações científico-tecnológicas e propomos que ela deva perpassar a reformulação discursiva dos três segmentos sociais diretamente envolvidos.

Cumprimentando as autoras pela oportunidade do diálogo, agradeço de público honradamente o convite.

\section{Referências}

1. Guillerme A. Réseau: genèse d'un mot. Les Cahiers de M édiologie, n. 3: "Anciennes nations, Nouveaux réseaux". [acessado $2001 \mathrm{Abr}$ 26]. Disponível em: http://www.mediologie.org/collection/03_nations/ vallet-guillerme.pdf

2. Possenti S. Teoria do discurso: um caso de múltiplas rupturas. In: Mussalim F, Bentes AC, organizadoras. Introdução à lingüística: fundamentos epistemológicos (volume 3). São Paulo: Cortez; 2004.

3. Foucault M. A ordem do discurso. Trad. Laura Fraga de Almeida Sampaio. 2a ed. São Paulo: Loyola; 1996.

4. Bakhtin M. M arxismo e filosofia da linguagem. $9^{a} \mathrm{ed}$. São Paulo: Hucitec; 2002.

\section{Informação, saúde, transdisciplinaridadee a construção de uma epistemologia social}

\author{
Information, health, transdisciplinarity \\ and the construction of a social epistemology
}

Regina $M$ aria $M$ arteleto ${ }^{5}$

\section{Introdução}

Os estudos em informação e comunicação naárea de saúde, em que pesem críticas neles incorporadas sobre a perspectiva difusionista elinear emissor-receptor que prevalece nos model os construídos para a orientação das políticas e ações de saúde, ainda se pautam muitas vezes por uma lógica de oferta informacional. Pode-seinferir que existem duas motivações principais para que se mantenha a visão da provisão de informações no setor de saúde e na sociedade em geral.

Em primeiro lugar, as novas tecnologias eletrônicas e digitais aumentam as possibilidades de organização, tratamento, recuperação e uso dos conhecimentos, o que acarreta uma abundância informacional que parece favorecer a visão unilateral dos processos de comunicação/informação. A segunda motivação dessa prevalência estaria relacionada à visão do que seja ciência presenteno imaginário científico esocial. Defato, e apesar da expansão e importância do conhecimento científico para diferentes esferas e atores sociais nos dias de hoje, ainda se faz presente no campo científico enas políticas de ciência e tecnologia uma visão positivista e elitista da ciência edas possibilidades de apropriação dos seus produtos e informações pela sociedade.

Nesse escopo, o artigo de Ilara Moares e M aria N élida Gómez, "Informação e Informática em Saúde: caleidoscópio contemporâneo da saúde", partindo do pressuposto da formação de um intercampo de informação e informática em saúde na contemporaneidade, composto por processos sócio- políticos e epistemológicos, pretende estudar as possibilidades de uma ação informacional no campo da saúde, capaz de ampliar as respostas do Estado na melhoria das condições de vida da população brasileira. 